\title{
Interactive comment on "Continuous measurements of isotopic composition of water vapour on the East Antarctic Plateau" by M. Casado et al.
}

\section{Anonymous Referee \#2 \\ Received and published: 21 April 2016}

This paper presents a highly valuable data set of stable water isotopes measured on the inland Antarctic site where deep ice cores have been retrieved in the past. The measurement captured different meteorological conditions (regime 1 and regime 2) and I'm convinced that there are things we can learn from this data. In particular, the fact that diurnal cycle of water vapor isotopes taken from $2 \mathrm{~m}$ above the surface corresponds to that of surface temperature rather than air temperature at $3 \mathrm{~m}$ above the surface is very interesting for me and may contribute to improve interpretation of ice core records. Furthermore, demonstration of the performance of a commercially available instrument (Picarro L2130-i) at the coldest mountainous region in the world is really valuable for our community. I have no doubt that the authors have done great 
work. However, in its current form, it is not easy to read for readers who are not familiar with water vapor isotope measurement using laser instruments. In order to understand their calibration procedure, I have re-read "section 2.4" several times. I strongly suggest that the authors should explain their calibration procedure both in the laboratory and in the field more clearly. The first data becomes benchmarks for the following studies. So, careful explanations are required to show us the robustness of their obtained new data. And, the manuscript seems "methods-heavy" which makes the results and discussion seem a little thin in this current version. Since this is the first data observed on the inland Antarctica, I recommend to add the general description as for observed isotopic features at there. I think the high d-excess values exceeding 50 is noteworthy, if these are true. I therefore recommend publication after addressing the following major points, and a few minor issures.

Major comments

1) Humidity-dependent bias correction The biggest concern of this study is a robustness of correction functions for humidity effects. As far as I know, the shape of this function (gradually increasing trend of isotopic values with decreasing humidity) is common for Picarro L2130-i (see Aemisegger et al., 2012, Bastrikov et al., 2014, Steen-Larsen et al., 2014 and so on). However, in Figure 4, the correction function is largely different between the field observation and the pre-campaign laboratory experiment. Surprisingly, the trend of this function for delta- 180 obtained from field campaign is opposite. I was looking forward to listening this reason, however there was no constructive explanation in the text. It just noted that "it is not unexpected" with referring to Aemisegger et al., (2012). I really disappointed this reply. Although the correction function can vary in time, as mentioned in Aemisegger et al., (2012), amplitude and shape of the correction function (in particular for latest Picarro) don't change so much. In addition, she pointed out that the effect of remaining water vapor concentration in the carrier gas might be a major source for their observed discrepancy in the correction function (lab vs. field experiment). In Figure 4, both delta-D and delta-180 values measured

Printer-friendly version

Discussion paper
Interactive

comment

\section{2}


in the field are plotted lower than those for laboratory experiment. Furthermore, the isotopic differences between laboratory experiment and field campaign become lager and larger with decreasing humidity. These raise me a concern about the influence of background water vapor with extremely depleted isotopic values in the dry air bottle (carrier gas). Since cylinder air is not completely dry, the influence of background water vapor should be carefully considered for their measurement. I strongly recommend to add the discussion as for the influence of remaining water vapor in the carrier gas (not only field campaign but also laboratory experiment). If they don't know the exact water vapor concentration in the carrier gas, the authors should consider the usage of the correction function obtained from the laboratory experiments as a substitute of that observed in the field.

2) Cryogenic moisture trapping There is a long history for water vapor trapping for isotope analysis. Even in the temperate region, a custom manufactured trap system has been used to satisfy required trapping efficiency, (e.g., Schch-Fischer et al., 1984, He and Smith, 1999, Uemura et al., 2008). Uemura et al. (2008) clearly mentioned that specially designed glass trap and careful treatment is necessary to get precise and accurate data for d-excess investigation. Therefore, the authors also have used custom manufactured trap system and have done some laboratory tests before going to the field. Addition of these informartion in the text must improve or strengthen the reliability of your data. Because vapor trapping system shown in Helliker et al. (2002) did not use in this study, it is not appropriate to refer to his paper here. I'm not sure if the authors used the same system shown in Steen-Larsen et al (2011), but this study also does not support reliability of your data because the temperature at Concordia station is much colder than at NEEM camp and flow rate used in this study is faster than their study.

Printer-friendly version

3) Calibration procedure for laser measurement Because the authors used custom manufactured calibration system, complete description for their calibration procedure is required. However, in its current form, it is very hard to understand their procedure 
except for expert of this field. For example, it was very hard to understand the following sentence: "Line 298: a series of calibration was performed in the laboratory from 100 to 1000 ppmv". Without the explanation of "a series of calibration", readers can't understand the meaning of this sentence. In section 2.4, there are several sentences similar to this. I recommend to reorganize and rewrite section 2.4 with the following information. 1. Schematic figure of self-designed calibration devise 2. Outline of the calibration procedure (order of three type of calibrations and their frequency) 3. Operating procedure for each of calibration (don't forget the description for the SMOW-SLAP linearity correction) 4 . Isotopic values of standard water for vapor sources 5 . Accuracy and precision of this method (Laboratory experiment) 6. Calibration procedure for field campaign 7. Data quality of field data (include uncertainty of d-excess)

Minor concerns

P4, I167: figure 2 -> Figure 2

P6, 1213: This noise -> These

P6 1221: realized -> carried out?

P6 1223: realized -> continued?

P6 1237: figure 3 -> Figure 3

P7 1258-259: "Because we are working.." is the same meaning of the following sentence "L261-262: Standard calibration..." Please remove one of the other.

P7 1265: Harvard Apparatus -> add parts number of this item

P8 1268: Bronkhorst devices -> add parts number of it

P12 1440: figure 6 -> Figure 6

P12 1459: figure 6 -> Figure 6

P13 1481: I think date expression is as follows: December 25th; 25th December; 25 
December; December the twenty-fifth; the twenty-fifth of December

I feel strange of the following expression: "December the 25th". Please check the expression of date.

P16 1580: figure 9 -> Figure 9

P17 1619: I can't catch the meaning of "slope at the mid height". Please rephrase it.

Interactive

comment

P16,1621: Figure 9 shows the negative peak of delta-180 at 18:00, corresponding to the minimum of surface temperature. Isn't this peak significant?

P18, Section 3.3: I can't understand why the authors stick to the discussion of slope value for the delta-D-deltaO plot. The slope is sensitive to the systematic bias so that the authors can't escape from the affect of large uncertainty of the measured isotopic values. As shown in Figure 10, I think that the most remarkable features of new data is extremely high d-excess values. So, I recommend to discuss the reason of these high values in here.

\section{References}

Aemisegger, F., Sturm, P., Graf, P., Sodemann, H., Pfahl, S., Knohl, A., \& Wernli, H. (2012). Measuring variations of $\delta 180$ and $\delta 2 \mathrm{H}$ in atmospheric water vapour using two commercial laser-based spectrometers: an instrument characterisation study. Atmospheric Measurement Techniques, 5(7), 1491-1511.

Bastrikov, V., Steen-Larsen, H. C., Masson-Delmotte, V., Gribanov, K., Cattani, O., Jouzel, J., \& Zakharov, V. (2014). Continuous measurements of atmospheric water vapour isotopes in western Siberia (Kourovka). Atmospheric Measurement Techniques, 7(6), 1763-1776.

He, H., \& Smith, R. B. (1999). Stable isotope composition of water vapor in the atmospheric boundary layer above the forests of New England. Journal of Geophysical Research: Atmospheres, 104(D), 11657. 
Helliker, B. R., Roden, J. S., Cook, C., \& Ehleringer, J. R. (2002). A rapid and precise method for sampling and determining the oxygen isotope ratio of atmospheric water vapor. Rapid Communications in Mass Spectrometry, 16(10), 929-932.

Schoch-Fischer, H., K. Rozanski, H. Jacob, C. Sonntag, J. Jouzel, G. Ostlund, and M. Geyh. (1984). Hydrometeorologicalfactorscon- trolling the time variation of $D, 18 O$ and $3 \mathrm{H}$ in atmospheric water vapour and precipitation in the northern westwind belt. Isotope Hydrology 1983, IAEA-publication, Vienna, Austria, 3-30

Steen-Larsen, H. C., Masson-Delmotte, V., Sjolte, J., Johnsen, S. J., Vinther, B. M., Breon, F. M., et al. (2011). Understanding the climatic signal in the water stable isotope records from the NEEM shallow firn/ice cores in northwest Greenland. Journal of Geophysical Research, 116(D6), D06108.

Steen-Larsen, H. C., Sveinbjörnsdóttir, A. E., Peters, A. J., Masson-Delmotte, V., Guishard, M. P., Hsiao, G., et al. (2014). Climatic controls on water vapor deuterium excess in the marine boundary layer of the North Atlantic based on 500 days of in situ, continuous measurements. Atmospheric Chemistry and Physics, 14(15), 7741-7756.

Uemura, R., Matsui, Y., Yoshimura, K., Motoyama, H., \& Yoshida, N. (2008). Evidence of deuterium excess in water vapor as an indicator of ocean surface conditions. Journal of Geophysical Research, 113(D19), D19114.

Interactive comment on Atmos. Chem. Phys. Discuss., doi:10.5194/acp-2016-8, 2016. 